\title{
Book Review: Change By Design: How Design Thinking Transforms Organizations and Inspires Innovation full, written by Tim Brown, ISBN - 978-0-06-233738-2, Harper Business, 2009
}

\author{
Shalini Singh \\ Centre of Computer Education, Institute of Professional Studies, University of Allahabad, India \\ shalinis455@gmail.com
}

\section{Keywords: * Demand * Design * Innovation * Brainstorming * Prototype *}

This book introduces design thinking, the collaborative process by which the designer's sensibilities and methods are employed to match people's needs with what is technically feasible and a viable business strategy. In short, design thinking converts need into demand. It's a human-centered approach to problem-solving that helps people and organizations become more innovative and creative. Design thinking converts need into demand. It is a human centered approach to problem solving that helps people and organizations become more innovative and more creative. This book introduces the idea of design thinking, the collaborative process by which designer's sensibilities and methods are employed to match people's needs. Tim Brown, who, himself started his career as an Industrial Designer, has shared his experience and thoughts in this book to show the upcoming designers the various trades of the designing which should be used in today's world. The book emphasizes not only on the area of other than purely designing or creating an object, but to be successful, one has to make it practical and acceptable in present as well in future.

The book, is divided into two parts, ten chapters in total, and also has an introductory chapter, where the author tries to visualize the foresight of the designers of Great Western Railway of England, Mr.Isambard kingdom Barnel. Mr. Barnel wanted passengers to have the sense of floating across the country side. Part 1 of the book has six chapters, dealing with the suggestions and ideas of how the designer should increase their thinking and how the upcoming designers' mind frame should be opened and ready to face the challenges. In chapter I, the author deals with how the leading maker of bicycle parts, Shimano of Japan, faced the challenge of getting low sale of bicycle in U.S.A. and how, with the help of observation and better retail strategy, he managed to improve the business. It further provides the mantra of innovation by inspiration, ideation and implementation. The author emphasizes that for a design idea, three things are must i.e. feasibility, viability and desirability. In Chapter II, the author further emphasizes upon design thinking by human contact and interaction. It gives a mantra, to explain observation and empathy; one has to learn from lives of others, field work to translate the above two into actual insight or into the design or developing the product so that it may be acceptable to the mass. Chapter III deals with the thinking of backstage by giving example of theatre where how the backstage was unorganized, and thereby the author, after bringing the client backstage, made it systematically. It further deals with convergent and divergent thinking. It deals with the theory of supremacy that ideas should be picked out not by person who is giving it, but by 
Shalini Singh; Book Review: Change By Design: How Design Thinking Transforms Organizations and Inspires Innovation full, written by Tim Brown, ISBN - 978-0-06-233738-2, Harper Business, 2009. Advances in I mage and Video Processing, Volume 6 No 4, August (2018); pp: 13-15

the usefulness of the idea to develop an ideal. The author had an idea to have a room with an environment in which the old ways of sticking notes and use of board should be done using the butterfly test. Chapter IV deals with the prototype; an example of kids is taken- for telling them that one must build up prototype before actually building it as they do in their games of building blocks. It further says not to over invest in it and also encourage the use of actual comments from consumer by Facebook or other sources so that it can improve it the prototyping as per one must have one's own idea and may or may not be plausible. But, it has to be an original, fresh idea and this would bring more success. Chapter $V$ deals with first hand design experience. It deals how operator enhanced its space to give a better customer experience. The author in this part deals, how he and his team proceeded to develop a RSO department in Mayo Clinic in which patients, designers, help professionals were all involved in a SPARC laboratory to transform the patient's experience. It gives a motto that an idea, to be successful, must be well executed. It further proposes that customers should be involved in developing ideas and they were the ultimate beneficiaries. The author in this chapter gives example of management by customer's involvement in Disney land and H.B.O. In the last chapter of Part I, the author desires on to tell the need of storytelling or the way to give an idea in the form of a story so that it may be more easily acceptable. It gives an example of Japan, where to curtail green house gasses, in terms of Kyoto protocol,I an idea of cool Biz was floated where, for a certain period of time, people wore casual clothes which soaked down Air Conditioners to help the environment. It makes use of audience as a story teller and also use of advertisement and meme's to successfully explain the customers about the design of the product. It emphasizes the use of storytelling to be an important tool in designers' kit to successfully design and develop an idea of product.

Part 2 of the book starts with Chapter 7 in which the author shows the way by which a bigger company like, Nokia and Zerox, develop their business and client base. In this chapter, main emphasis has been given on the desirably based approach. To simplify the chapter, discusses various ways in which a company designs itself to cater the needs of the business. It also gives example of Nano of Tata Motors to share the ways of growth. It also deals with the dedicated spaces and workshops, to improve and build new products, which will be catering the demands of the new generation. In Chapter 8 of the book, the author goes further explaining the approach of design theory, it goes to the level where it proposes that, in order to develop a design, one has to start with scratch i.e. "The Slogan How Might We". It gives an example of developing ideas for U.S. Transport security administrator, neither of which invented the idea of renting the DVD online. It gave emphasis upon social contract theory which involves the public also i.e. nurse at Kaiser, the production workers in Toyota ,and Wolf Park in the best city. In the $9^{\text {th }}$ chapter, the author talks on another dimension of thinking, by giving illustration of Aravind eye Hospital in which Dr G. Venkatswamy, who is the entrepreneur of the said hospital, in which lakhs of operations were done by the doctors, and also an example of International Development Enterprises, based at Delhi which provide low cost solutions to the farmers of the vicinity .In other words, mixing sustainable business approach and measuring profit in social impact of it. It ultimately goes to apply the design thinking in the upliftment and betterment of the society. The last and final chapter summarizes the gist of all the previous chapters by putting the ultimate points, that all the above thoughts and suggestions are only good, if it is used by common designers in their day to day routine. It emphasizes the human centered approach. It also says that there should be free flow in all parts of organization of ideas; it should be more unique and successful. It says of getting professional help. It emphasizes on the point of observation, and to be more curious so that one is able to create new ideas and designs. It gives idea of carrying a sketch pad and capture photos to be 
able to capture the observations and ideas on the first hand. Thus, the author, by this book has imparted his experience by giving examples of leading companies and designers. He has given a motto that "To be successful, one has to be able to adapt, and think forward upon the need and upcoming demands of the society and people".

\section{About the Author}

Shalini Singh received her MCA degree in 2007 from Indira Gandhi National Open University, M.Voc. in Fashion Design \& Technology in 2017 from Centre of Fashion Design and Technology, University of Allahabad. She obtained her P. hd. in Computer Science on the topic of 'Innovative Design Strategy through Computer in Fashion Technology' in 2017 from the Uttar Pradesh Rajarshi Tandon Open University. She joined as a Resource Person in Centre of Computer Education, University of Allahabad in 2008. Her area of interest is to experiment with computer aided design software.

Mailing Address: Centre of Computer Education, Institute of Professional Technology, University of Allahabad, Mob: +91-9616551481, Allahabad-211002, U.P. (India), E-mail: shalinis455@gmail.com 